\title{
Applied Forces in the Handling Unit Fixation Mechanism
}

\author{
Leopold HRABOVSKY*, Tomas MLCAK, Vaclav ZACEK
}

\begin{abstract}
The paper presents a construction design of a testing device, which was built for the purpose of checking the functional properties of the movement fixation mechanism of handling units, which is used for locking pallets with cars in place in some parking houses, developed by the enterprise KOMA Industry s.r.o. The testing device uses two positioning tables, whose moving parts are attached perpendicular to each other in the frame of the testing device. A pallet lock is attached to the sliding part of the vertical positioning table, which consists of three basic parts: body, pulley holder and compression coil spring. A plate is attached to the sliding part of the horizontal positioning device which is adapted to receive the stop of the fixation mechanism. This paper presents values of the measured vertical forces acting on the force transducer, which were generated by the reshaped coil spring with a wire of circular cross-section during the rolling of the pallet lock roller over the sloped surface of the stop. It presented an experimental procedure and the results of the measured vertical forces exerted by a reshaped coil spring with a wire of circular cross-section on the force sensor during the insertion of the pulley roller into the gap between the two end faces of the stop assembly. The experimental procedure and the results of the measured vertical forces exerted by the reshaped coil spring with a wire of circular cross-section on the force sensor during sliding of the lock pulley roller out of the gap in the stop are given in one of the chapters. The conducted experimental measurements of the functional properties of the fixation lock of the pallet and the acquired values of acting vertical forces will serve to optimize the attaching of pallet fixation locks to the steel girders of the structure of the cell rack parking space of the automatic parking house, over which the chain conveyer transports pallets with vehicles into specified parking positions.
\end{abstract}

Keywords: coil spring compression force; fixation mechanism; fixation mechanism lock; fixation mechanism stop; testing device

\section{INTRODUCTION}

The fixation mechanism is used in the automated parking garage to lock, and securing against the spontaneous movement, the parked vehicles on pallets in the units of the rack parking system.

Hrabovsky and Molnar [1] presents the design of the fixation mechanism of pallets, which is installed in automatic parking houses (hereinafter referred to as APH) in Ostrava - FEI and in the town of Slaný.

The Slánský APH was put into operation in 2013, however it was loss-making in the long term due to low utilization in the years 2013 to 2019 and it was decided by the City Council of the royal town of Slaný that the APH will be discontinued.

The arguments of the city Slaný for closing the APH, built by KOMA-Industry s.r.o., were that, since the beginning of the operation, the APH manifested a number of technical problems and inconsistencies, long waiting times for parking and issuing of vehicles, low usage and high operational economic costs.

The low usage of the APH may be explained by the fact that many citizens of the city Slaný do not park in the APH out of an inner determination not to, others complained that the APH had some errors at the beginning, and did not trust it since then. The underutilization of the APH is also given by the fact that the facility does not dispatch vehicles as fast (it was expected that the unloading of vehicles would take under a minute, the average waiting time is, however, three minutes) as the supplier had originally promised.

The city Slaný came to the decision to lower parking prices (hourly, monthly, even yearly) in order to eliminate the disinterest in the APH. However, the financial revenues during discounted parking could not, despite increased usage of the APH, significantly lower the operational economic costs. The city Slaný was forced to set aside a large amount of its budget to keep the APH running. The long-term economic burden of running the APH led the city Slaný in the year 2019 to end the operation of the APH.
Company KOMA-Industry s.r.o ran the operation of the APH until its termination in order to remove its shortcomings, such as unreliability and long waiting time during car unloading.

The loading and unloading a vehicle into and from a rack cell in the APH in Slaný is done by specific technological mechanisms, working in automatic mode, controlled by a computer system.

The sophisticated technology which consists of handling equipment for transporting pallets with vehicles in horizontal and vertical planes, and transporting equipment, guides the fully-automatically pallets into the predetermined positions into a specified cell in the rack storage.

After loading the pallet into the parking rack cell with the help of the chain transporting mechanism, it is necessary to make sure that the pallet stays secure in the specified position. The fixation of the pallet is controlled by the mechanical fixation mechanism [1], which runs without error only if it is optimally adjusted.

A testing device was constructed to demonstrate that the pallet fixation mechanism fulfills its function without error, and to verify the optimal adjustment, see Fig. 4 and Fig. 6, which enabled us to simulate the operational conditions, which are present during the guiding of the pallet with the car into the pallet of the Slaný APH parking rack cell.

\section{HANDLING UNIT FIXATION MECHANISM TESTING DEVICE INTRODUCTION}

The handling unit fixation mechanism testing device, construction design, see Fig. 1, which are the steel $2.2 \mathrm{~m} \times$ $5.3 \mathrm{~m}$ pallets in the APH in Slaný, consists of a steel frame structure 1 , which is welded from thin steel closed rolled profiles with a square cross-section of $20 \mathrm{~mm} \times 20 \mathrm{~mm}$, profile thickness $2 \mathrm{~mm}$.

The pallet fixation mechanism [1] consists of two fundamental components: the pallet lock 2 and the stop 3 .

In the pallet fixation mechanism testing device, the 
pallet lock 2 is attached to the board 5 of the vertical positioning table 6 with two screws 4 . On the top surface of the plate 5 (dimension $150 \mathrm{~mm} \times 150 \mathrm{~mm}$ ), two M8 threaded holes are drilled (through the entire thickness of the $10 \mathrm{~mm}$ plate 5). The vertical axis of the first hole is 39 $\mathrm{mm}$ from the left edge of the plate 5 . The horizontal axis of the first hole is $54 \mathrm{~mm}$ from the lower edge of the plate 5 . The threaded portion of the left screw is screwed into the internal thread M8 of the first bore 4 (see left view Fig. 1b) which holds the pallet lock 2 to the plate 5 . The vertical axis of the second opening is $61 \mathrm{~mm}$ from the right edge of the plate 5 . The horizontal axis of the second opening is 84 $\mathrm{mm}$ from the lower edge of the plate 5. The threaded portion of the left screw is screwed into the internal thread M8 of the right bore 4 (see left view Fig. 1b) which attaches the pallet lock 2 to the plate 5 . The horizontal spacing 50 $\mathrm{mm}$ and vertical spacing $30 \mathrm{~mm}$ of the M8 threaded holes on the top surface of the plate 5 is identical to the spacing of the holes in the pallet lock body 2 .

Plate 5 is fastened to the platform of the vertical positioning table 6 with $4 \times$ screws 7 ; under each screw head 7 there is a washer.

The upper and lower end of vertical positioning table 6 is attached to the steel frame 1 by 2 screw connections 8 .
The Stop 3 is attached to the plate 9 of the horizontal positioning table 10 with two screws 11 and 12 .

On the top surface of the plate 9 (dimension $150 \times 150$ $\mathrm{mm}$ ), two M8 threaded holes are drilled (through the entire thickness of the $10 \mathrm{~mm}$ plate 5). The vertical axis of the first hole is $18 \mathrm{~mm}$ from the left edge of the plate 9 . The vertical axis of the second opening is $75 \mathrm{~mm}$ from the lower edge of the plate 9 . The threaded portion of the screw is screwed into the internal thread M8 of the first bore 11 (see left view Fig. 1b) which attaches the stop 3 to the plate 9. The vertical axis of the second opening is $77 \mathrm{~mm}$ from the right edge of the plate 9 . The threaded portion of the screw is screwed into the internal thread M6 of the bore 12 (see left view Fig. 1b) which attaches the stop 3 to the plate 9.

Plate 9 is fastened to the horizontal positioning table platform 10 with 4 pcs of screws 7 . Front and back ends of the vertical positioning table 10 are attached to the steel frame 1 by 2 screw connections 10 .

A steel arm 15 (which switches the limit switch contacts 13 to a desired position is fixed by four screws to the left side surface of the pallet lock 2) is fastened with a screw to the face of the plate 9 (see left view Fig. 1b).
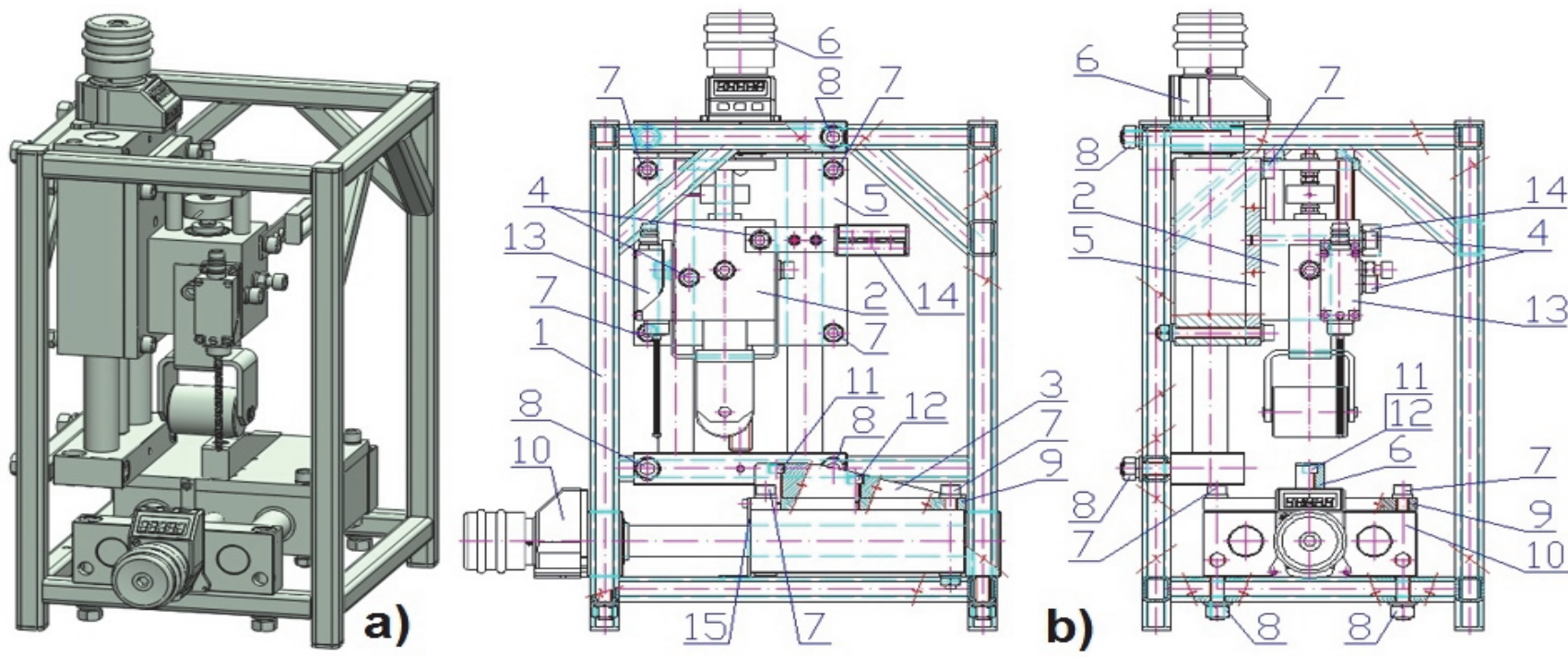

Figure 1 The Handling unit fixation lock testing device, design a) 3D in SolidWorks 2012 SP 5.0, b) 2D in AutoCAD 2010

\section{APPLIED FORCES IN THE MOVEMENT FIXATION MECHANISM OF HANDLING UNITS}

The weakest link in the reliability of the automatic parking system is the fixation mechanism, which is presented as a pallet brake. In terms of mechanical principle, this is not a real brake, but a locking mechanism with a spring and a rotary pulley which, in addition to locking the pallet in the parking position, is able to partially brake and stop the pallet. The pallet with car must be parked in the rack cell in proper position where the pallet is secured against spontaneous movement when the fixation mechanism pulley is engaged in the brake haunch cut-out.

The purpose of the paper was to determine the actual theoretically acting forces of the fixation mechanism and kinematic ratios in play during the guiding / pushing of the locking brake pulley into / out of the recess in the form of a circular cut-out sector of the brake mounted on the pallet.

The first design variant of the pallet brake of the pallet locking system, installed in the APH in the city of Brno, is listed in $[3,8]$. The second design variant of the pallet brake system of the pallet locking system [2, 3], used in APH in Brno, including experimentally obtained forces that are generated when the brake pulley is pressed into the circle-shaped recess in the brake is described in [2].

The structural design of the fixation pallet lock, which is used in APH in Slaný and APD Ostrava - FEI is described in [1].

\subsection{Applied Forces During the Rolling of the Pallet Pulley Roller of the Fixation Mechanism on the Sloped Surface of the Stop}

The stop 3 of pallet lock 2 is fastened to the plate 9 of the horizontal positioning table 10 (see Fig. 1b) with 
screws 11 and 12. As a result of a change in the position of the moveable part of the horizontal positioning table 10 , the pallet lock pulley 2 (whose body is fixed by 2 screws 4 to the plate 5 of the vertical positioning table 6) begins to contact the sloped part of the stop 3.

The moment the pallet lock 2 roller contacts the sloped part of the stop 3, it is possible to vertically adjust the moveable part of the vertical positioning table 6 . The structural dimensions $\left(H_{z} / \mathrm{m}, h_{z} / \mathrm{m}, \alpha / \mathrm{deg}\right)$, see Fig. 2a, of the stop 3 and pallet lock 2 pulley $\left(R_{k} / \mathrm{m}\right)$ allow us to determine the horizontal height $h / \mathrm{m}$ when the pallet lock 2 pulley makes initial contact with the sloped part of back stop 3. The horizontal height $h / \mathrm{m}$, see Fig. 2b, defines the vertical distance of the horizontal axis of the pallet lock 2 pulley from the horizontal plane of the bottom surface of the stop 3.

The minimum distance $h_{\min } / \mathrm{m}$ of the horizontal axis of the pallet lock 2 pulley from the plane of the bottom surface of the stop 3, viz Fig. 2b, must be adjusted by vertically moving the vertical positioning table 6 to the Eq. (1).

$h_{\min } \geq R_{k}+h_{z}$

The maximum distance $h_{\max } / \mathrm{m}$ of the horizontal axis of the pallet lock pulley 2 from the lower surface of the back stop 3 is necessary to adjust to ensure contact between the pallet lock 2 roller and the sloped part of the stop 3, see Fig. 2b. This is achieved by vertically adjusting the vertical positioning table 6 to the Eq. (2).

$h_{\max } \leq R_{k}+H_{z}$

If it is ensured that the horizontal axis of the pallet lock 2 pulley is located in the interval $h_{\min } \leq h \leq h_{\max }$ from the lower surface of the stop 3 , then it is possible to determine the value of $y[\mathrm{~m}]$ according to the Eq. (3), see Fig. 2a, which defines the vertical distance of the horizontal axis of the pallet lock 2 pulley from the horizontal plane by $h_{z} / \mathrm{m}$ from the lower surface of the stop 3.

$$
\begin{aligned}
y & =h_{1}+h_{2}=R_{k} \cdot \cos \alpha+\left(l_{1}+l_{2}\right) \cdot \operatorname{tg} \alpha= \\
& =R_{k} \cdot \cos \alpha+\left(R_{k} \cdot \sin \alpha+l_{2}\right) \cdot \operatorname{tg} \alpha
\end{aligned}
$$

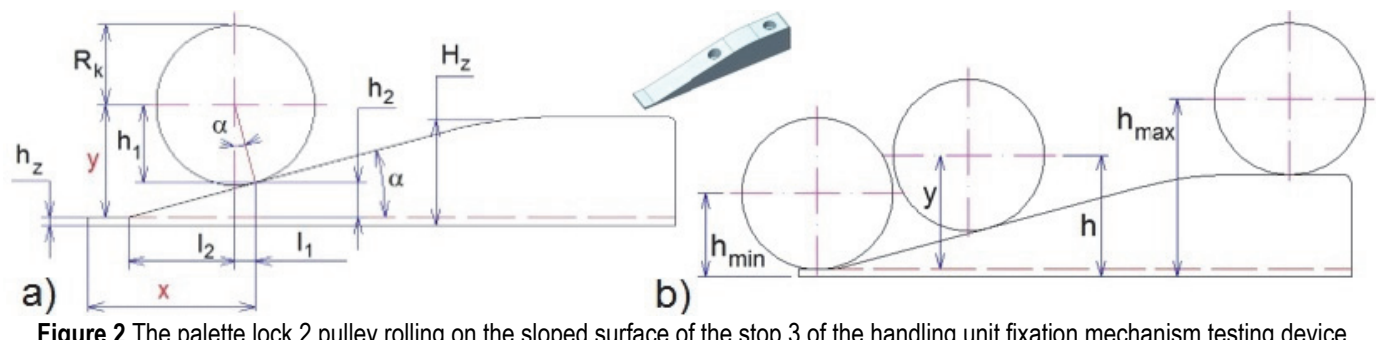

Figure 2 The palette lock 2 pulley rolling on the sloped surface of the stop 3 of the handling unit fixation mechanism testing device

The 3D model and 2D structural design of the pallet lock 2 which is used in APH in Slaný is shown in Fig. 3. The magnitude of the contact force of the pallet lock 2 acting on the contact surface 3 can be influenced in two ways:

- the first way is to set the vertical distance $\mathrm{h}[\mathrm{m}]$, see Fig. $2 \mathrm{~b}$, which can be achieved by attaching the body of the pallet lock by 2 (screws 4, see Fig. 1) to the beams of the steel structure of the parking rack in APH in a fitting manner, see [1].

- the second method is to prestress the compression coil spring, see Fig. 3, which is installed in the pallet lock 2.

Inside a real APH, the rotating part (pulley) roller of the pallet lock 2 does not contact the upper surface of the front part of the stop 3 (height $h_{\text {of }}=2 \mathrm{~mm}$ ), see Fig. 2a. The pallet lock 2 is mechanically attached to the steel structure of the parking rack so that the roller of the pallet lock 2 is $h_{2}=13 \mathrm{~mm}$ distant (see Fig. 2a) from the top of the front of the stop 3 and approaches the sloped surface mid height of the stop 3. In the APH in Slaný the pallets 2 are fitted with compression coil springs [6] stiffness $k_{p}=$ $3.98 \mathrm{~N} / \mathrm{mm}$ [4].

The cylindrical spring of free length $L_{0}=122.75 \mathrm{~mm}$ is compressed inside the pallet lock 2 by at least $\Delta L_{\min } / \mathrm{m}$ Eq. (4).

$$
\Delta L_{\min }=\left(L_{0}-h_{z p}\right)=122.75-104=18.75 \mathrm{~mm}
$$

where $h_{z p} / \mathrm{mm}$ is the vertical distance of components of the pallet lock 2, see Fig. 3 .

The initial spring compression $\Delta L / \mathrm{m}$ can be adjusted using the set screw located on the top plate of the pallet lock 2, see Fig. 3. The spring generates an initial minimum compressive force $F_{p \min } / \mathrm{N}$, Eq. (5).

$$
F_{p \min }=\Delta L_{\min } \cdot k_{p}=18.75 \cdot 3.98=74.6 \mathrm{~N}
$$

When the pallet lock 2 pulley is rolling over the surface of the stop 3 (On the testing device, see Fig. 4, is achieved by displacing the movable part of the horizontal positioning table 10 , by increasing the distance $x / \mathrm{m}$, see Fig. 2a) in the moment it is rolling over the top surface of the back part of the stop 3 (height $H_{z} / \mathrm{m}$ ), the pulley holder of the pallet lock 2 is inserted into the body of the pallet lock 2 by $h_{d t} / \mathrm{m}$, Eq. (6).

$$
\begin{aligned}
h_{d t} & =H_{z}-h_{2}-h_{z}=27-13-2=12 \mathrm{~mm} \\
F_{p 1} & =\left[L_{\min }+\left(h_{3}-h_{d t}\right)\right] \cdot k_{p}= \\
& =[18.75+(24-12)] \cdot 3.98=122.4 \mathrm{~N} \\
h_{21} & =h_{2}+h_{d t}=13+12=25 \mathrm{~mm} \\
F_{p 1} & =\left[L_{\min }+\left(h_{21}-h_{2}\right)\right] \cdot k_{p}= \\
& =[18.75+(25-13)] \cdot 3.98=122.4 \mathrm{~N}
\end{aligned}
$$



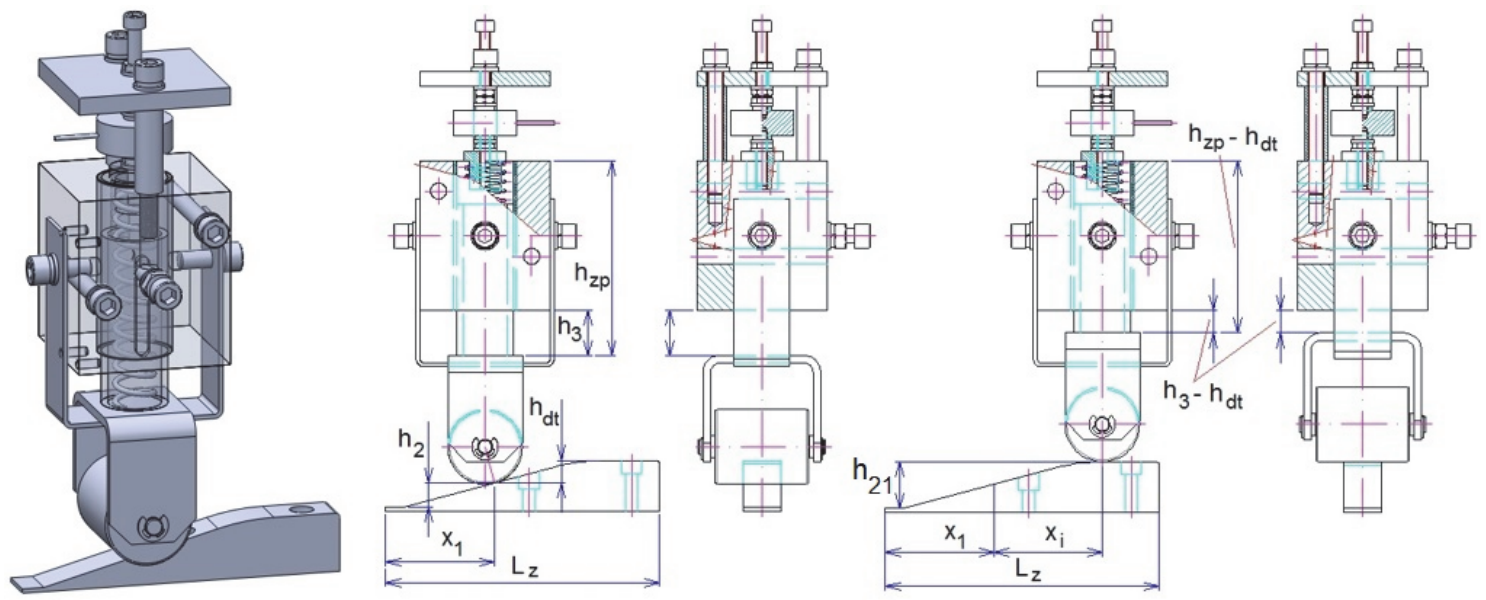

Figure 3 The palette lock 2 pulley rolling on the sloped surface of the stop 3 of the handling unit fixation mechanism

Table 1 Vertical forces when pallet lock roller is rolling on the sloped surface of the stop

\begin{tabular}{|c|c|c|c|c|c|c|c|c|}
\hline$x_{i} 10^{-3} / \mathrm{m}$ & \multirow{4}{*}{$\mathrm{i}$} & 0 & 5 & 10 & 15 & 20 & 25 & 30 \\
\hline$\left(x_{1}+x_{i}\right) 10^{-3} / \mathrm{m}$ & & 58.52 & 63.52 & 68.52 & 73.52 & 78.52 & 83.52 & 88.52 \\
\hline$h_{2 i} 10^{-3} / \mathrm{m}$ & & 13.00 & 14.34 & 15.68 & 17.02 & 18.36 & 19.70 & 21.04 \\
\hline$F_{p i} / \mathrm{N}$ & & 74.6 & 79.9 & 85.3 & 90.6 & 95.9 & 101.3 & 106.6 \\
\hline \multirow{5}{*}{$F_{y i} / \mathrm{N}$} & 1 & 73.9 & 79.4 & 84.7 & 89.8 & 95.7 & 100.6 & 105.8 \\
\hline & 2 & 74.1 & 79.8 & 85.2 & 90.2 & 95.3 & 100.9 & 105.9 \\
\hline & 3 & 73.8 & 79.6 & 84.6 & 89.7 & 95.4 & 100.5 & 105.5 \\
\hline & 4 & 73.9 & 79.5 & 84.8 & 89.9 & 95.3 & 100.6 & 105.9 \\
\hline & 5 & 74.3 & 79.6 & 84.9 & 90.2 & 95.6 & 100.7 & 106.1 \\
\hline \multicolumn{2}{|l|}{$F_{y(x i)} / \mathrm{N}$} & $74.1 \pm 0.1$ & $79.6 \pm 0.2$ & $84.8 \pm 0.3$ & $90.0 \pm 0.3$ & $95.5 \pm 0.2$ & $100.7 \pm 0.2$ & $105.8 \pm 0.3$ \\
\hline$x_{i} 10^{-3} / \mathrm{m}$ & \multirow{4}{*}{$\mathrm{i}$} & 35 & 40 & 45 & 50 & 55 & 60 & \\
\hline$\left(x_{1}+x_{i}\right) 10^{-3} / \mathrm{m}$ & & 93.52 & 98.52 & 103.52 & 108.52 & 113.52 & 118.52 & \\
\hline$h_{2 i} 10^{-3} / \mathrm{m}$ & & 22.33 & 23.38 & 24.16 & 24.68 & 24.96 & 25.00 & \\
\hline$F_{p i} / \mathrm{N}$ & & 111.7 & 115.9 & 119.0 & 121.1 & 122.2 & 122.4 & \\
\hline \multirow{5}{*}{$F_{y i} / \mathrm{N}$} & 1 & 110.7 & 115.3 & 118.6 & 120.7 & 121.8 & 121.7 & \\
\hline & 2 & 110.4 & 115.2 & 118.4 & 120.9 & 121.7 & 121.8 & \\
\hline & 3 & 110.8 & 114.9 & 118.7 & 120.5 & 121.6 & 121.7 & \\
\hline & 4 & 110.9 & 115.1 & 118.4 & 120.6 & 121.7 & 121.7 & \\
\hline & 5 & 111.3 & 115.2 & 118.5 & 120.7 & 121.6 & 121.7 & \\
\hline \multicolumn{2}{|l|}{$F_{y(x i)} / \mathrm{N}$} & $110.8 \pm 0.4$ & $115.1 \pm 0.2$ & $118.5 \pm 0.2$ & $120.7 \pm 0.2$ & $121.7 \pm 0.1$ & $121.7 \pm 0.1$ & \\
\hline
\end{tabular}

The vertical distance $h_{21}[\mathrm{~m}]$ of the pulley of the pallet lock 2 from the top surface of the front of the back stop 3, see Fig. 3, can be expressed according to the relation Eq. (8); at this point the spring exerts a compressive force of $F_{p 1} / \mathrm{N}(7)$, Eq. (9).

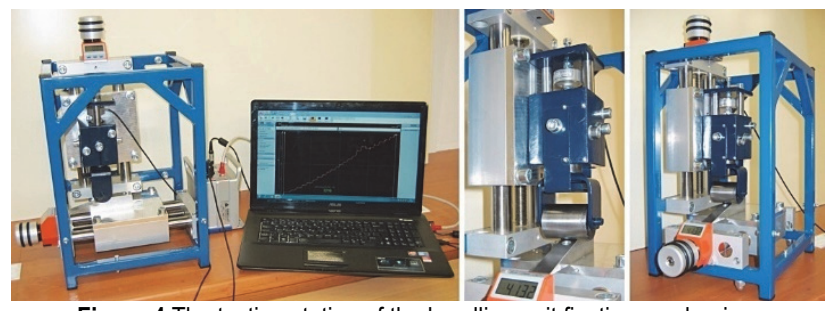

Figure 4 The testing station of the handling unit fixation mechanism

Simulations were carried out on the handling unit fixation mechanism testing device, see Fig. 4, in order to verify the smooth operation of the fixation mechanism and to obtain real values of the acting forces $F_{y i} / \mathrm{N}$ that are generated in the body of the pallet lock 2 , ie. the forces applied to the force transducer [6] derived by compressing the spring [5] the moment the pallet lock 2 pulley is rolling over along the sloped surface of the stop 3 (provided that $h_{2}=13 \mathrm{~mm}$, which corresponds to $\left.x_{1}=58.52 \mathrm{~mm}\right)$.

In gradually changing the position $\left(x_{i+1}=x_{i}+5 / \mathrm{mm}\right.$, for $x_{i}=0 \mathrm{~mm}$ to $60 \mathrm{~mm}$ ) of the moveable part of the horizontal positioning table 10 the values of pressure force $F_{y i} / \mathrm{N}$ were (detected by strain gauge force sensor) [7]) read and recorded PC in DEWESoft X2 SP5 software environment into Tab. 1.

The measured values (for $n=5$ repeated measurements under the same conditions) of the compressive force $F_{y i} /$ $\mathrm{N}$, were using Student's distribution $[1,4,6]$ (for the selected risk $\alpha=5 \%$, number of measurements $n=5$ and Student's coefficient $t_{5 \%, 5}=2.78$ ) used to calculate extreme errors calculated by $\kappa_{5 \%, 5(x i)}[N]$ and the results of measured forces in the form of $F_{y(x i)}=F_{s y(x i)}+\kappa_{5 \%, 5(x i)} / \mathrm{N}$, where $F_{s y(x i)} / \mathrm{N}$ is the arithmetic mean of all measured values of $F_{y i} / \mathrm{N}$ for the respective position $x_{i} / \mathrm{m}$, were recorded into the bottom row of Tab. 1 .

\subsection{Applied Forces When Pushing the Pallet Lock Roller of the Fixation Mechanism Into the Gap in the Stop Assembly}

The pallet lock 2 is fastened to the plate 5 of the moving part of the vertical positioning table 6 with screws 4, see Fig. 1b. The moving part of the vertical positioning table 6 is (in the beginning of the experimental measurements) moved in the vertical plane to a position that ensures the distance $h_{2}=13 \mathrm{~mm}$ (see Fig. 5) of the pallet lock pulley 2 from the top surface of the front of the stop 3.

The pallet lock 2 stop 3 is fastened to the plate 9 of the horizontal positioning table 10 (see Fig. 1b) with screws 11 and 12. Changing the position of the movable part of the 
horizontal positioning table 10 causes the pallet lock pulley 2 to, at some point, contact the rounded portion on the front face of the stop 3 .

The origin of the coordinate system $\left[x_{0} ; y_{0}\right]$ is selected up to the point $\left[r ; h_{z}+h_{2}\right]=[2 ; 15] \mathrm{mm}$ relative to the lower left edge of the stop 3, see Fig. 5.
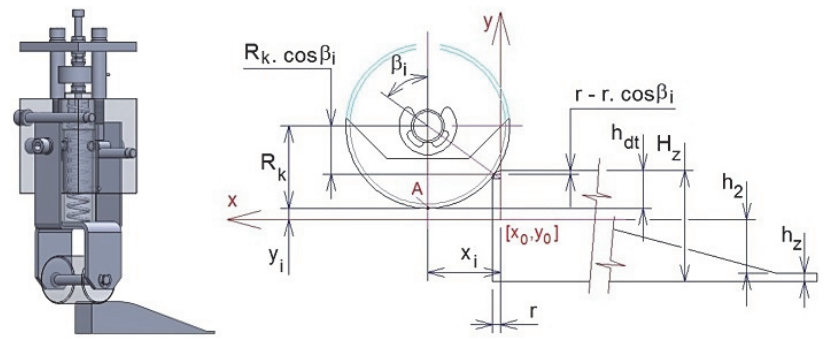

Figure 5 The pallet pulley 2 rolling over the rounded edge of the stop 3

When the pallet lock 2 pulley is rolling along the rounded edge of the stop 3 (on the testing device, see Fig. 6 , this is done by moving, i.e. extending the distance of the movable part of the horizontal positioning table 10) using Fig. 5, it is possible to numerically express the horizontal distance $x_{i} / \mathrm{m}$ according to the Eq. (12) and angle $\beta_{i} /$ deg according to Eq. (11).

$h_{d t i}=H_{z}-h_{2}-h_{z}-y_{i}$

$h_{d t i}=R_{k}-R_{k} \cdot \cos \beta_{i}+r-r \cdot \cos \beta_{i} \Rightarrow$

$\Rightarrow \beta_{i}=a \cos \left(\frac{R_{k}+r-h_{d t i}}{R_{k}+r}\right) / \operatorname{deg}$

$x_{i}=R_{k} \cdot \sin \beta_{i}+r \cdot \sin \beta_{i}=\sin \beta_{i} \cdot\left(R_{k}+r\right)$

Tab. 2 gives the calculated angles $\beta_{i} /$ deg and outlying $x_{i} / \mathrm{m}$ of point $\mathrm{A}$ of the pallet lock 2 pulley from the origin of the coordinate system depending on the vertical position $y_{i} / \mathrm{m}$ point $\mathrm{A}$ of the pallet lock 2 pulley. Tab. 2 also gives the values of compressive force $F_{p i} / \mathrm{N}$ of the spring acting on the force sensor when the spring is deformed $L_{i}=\Delta L_{\min }$ $+y_{i} / \mathrm{m}$ and compressive forces $F_{p i(y i)} / \mathrm{N}$, which defines the increment of the compressive force when the spring of the assumed original length $\Delta L_{\min } / \mathrm{m}$ is shortened by the value of $y_{i} / \mathrm{m}$.

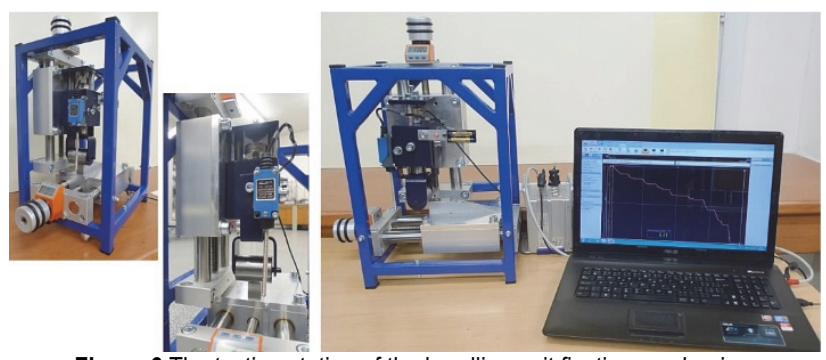

Figure 6 The testing station of the handling unit fixation mechanism

Measurements were made on the testing device of the fixation mechanism of the handling units, see Fig. 6, to experimentally obtain the true values of the applied forces $F_{y i} / \mathrm{N}$ that are generated in the body of the pallet lock 2, i.e. the forces applied to the force transducer [6] derived by compression of the spring [5] when pushing the pulley of the pallet lock 2 into the gap between the two end faces of the stop 3 assembly [1].

In the experiment, the pulley of the pallet lock 2 was first guided to a distance of $r=2 \mathrm{~mm}$ from the front edge of the stop 3 (lower roller surface of the pallet lock 2 of the stop 3 (lower roller surface of the pallet lock 2 is located at $\left[x_{0} ; y_{1}\right]=[0 ; 12] \mathrm{mm}$, see Fig. 5) and then the moveable part of the horizontal positioning table 10 to which a stop was attached using screws (11 and 12 see Fig. 1b), was moved incrementally by $x_{i} / \mathrm{m}$ in the horizontal plane.

By relationship (13) it is possible to theoretically quantify the value of $y_{i} / \mathrm{m}$ (i.e. displacement of the pallet lock 2 pulley in the direction of the " $y$ " axis) depending on the $x_{i} / \mathrm{m}$ position of the moveable part of the horizontal positioning table 10, see second row of Tab. 3 .

$$
\begin{aligned}
& y_{i}=H_{z}-\left(h_{z}+h_{2}\right)-\left(1-\cos \beta_{i}\right) \cdot\left(R_{k}+r\right), \\
& \text { where } \beta_{i}=a \sin \left(\frac{x_{i}}{R_{k}+r}\right)
\end{aligned}
$$

\begin{tabular}{|c|c|c|c|c|c|c|c|}
\hline$y_{i} 10^{-3} / \mathrm{m}$ & 0 & 1 & 2 & 3 & 4 & 5 & 6 \\
\hline$\beta_{i} / \operatorname{deg}$ & 62.96 & 60.00 & 56.94 & 53.78 & 50.48 & 47.01 & 43.34 \\
\hline$x_{i} 10^{-3} / \mathrm{m}$ & 19.60 & 19.05 & 18.44 & 17.75 & 16.97 & 16.09 & 15.10 \\
\hline$F_{p i} / \mathrm{N}$ & 74.6 & 78.6 & 82.6 & 86.5 & 90.5 & 94.5 & 98.5 \\
\hline$F_{p i(y i)}=F_{p i}-F_{p \min } / \mathrm{N}$ & 0.0 & 4.0 & 8.0 & 11.9 & 15.9 & 19.9 & 23.9 \\
\hline$y_{i} 10^{-3} / \mathrm{m}$ & 7 & 8 & 9 & 10 & 11 & 12 & \\
\hline$\beta_{i} / \operatorname{deg}$ & 39.40 & 35.10 & 30.27 & 24.62 & 17.34 & 0 & \\
\hline$x_{i} 10^{-3} / \mathrm{m}$ & 13.96 & 12.65 & 11.09 & 9.17 & 6.56 & 0.00 & \\
\hline$F_{p i} / \mathrm{N}$ & 102.5 & 106.4 & 110.4 & 114.4 & 118.4 & 122.4 & \\
\hline$F_{p i(y i)}=F_{p i}-F_{p \min } / \mathrm{N}$ & 27.9 & 31.8 & 35.8 & 39.8 & 43.8 & 47.8 & \\
\hline
\end{tabular}

Table 2 Point angle and distance A of the pallet lock 2 pulley from the beginning of the coordinate system

\begin{tabular}{|c|c|c|c|c|c|c|c|c|c|c|c|c|}
\hline$x_{i} \cdot 10^{-3} / \mathrm{m}$ & \multirow{4}{*}{$\mathrm{i}$} & 0 & 2 & 4 & 6 & 8 & 10 & 12 & 14 & 16 & 18 & 19.6 \\
\hline$y_{(x i)} \cdot 10^{-3} / \mathrm{m}$ & & 12.00 & 11.91 & 11.63 & 11.17 & 10.49 & 9.60 & 8.44 & 6.97 & 5.10 & 2.65 & 0 \\
\hline$F_{p(x i)} / \mathrm{N}$ & & 122.4 & 122.0 & 119.1 & 116.4 & 112.8 & 108.2 & 102.3 & 94.9 & 85.2 & 74.6 & 74.6 \\
\hline$F_{p(x i)}-F_{p \min } / \mathrm{N}$ & & 47.8 & 47.4 & 46.3 & 44.5 & 41.8 & 38.2 & 33.6 & 27.7 & 20.3 & 10.6 & 0.0 \\
\hline \multirow{5}{*}{$F_{y i(x i)} / \mathrm{N}$} & 1 & 49.4 & 46.4 & 43.3 & 39.9 & 36.4 & 32.4 & 29.8 & 23.3 & 13.1 & 8.3 & 0.0 \\
\hline & 2 & 49.6 & 46.2 & 43.9 & 41.4 & 37.7 & 33.1 & 29.8 & 23.5 & 12.4 & 7.6 & 0.0 \\
\hline & 3 & 48.3 & 45.7 & 42.7 & 40.3 & 37.3 & 32.8 & 29.6 & 21.9 & 11.7 & 6.8 & 0.0 \\
\hline & 4 & 49.2 & 46.3 & 43.1 & 39.8 & 37.2 & 32.6 & 29.7 & 23.4 & 12.9 & 8.2 & 0.0 \\
\hline & 5 & 48.8 & 45.9 & 43.4 & 40.8 & 36.9 & 32.9 & 29.6 & 22.8 & 12.6 & 7.6 & 0.0 \\
\hline \multicolumn{2}{|l|}{$F_{y s(x i)} \pm \kappa_{(x i)}[N]$} & $\begin{array}{l}49.1 \\
\pm 0.6\end{array}$ & $\begin{array}{r}46.1 \\
\pm 0.4\end{array}$ & $\begin{array}{r}43.3 \\
\pm 0.5\end{array}$ & $\begin{array}{r}40.4 \\
\pm 0.8\end{array}$ & $\begin{array}{l}37.1 \\
\pm 0.6\end{array}$ & $\begin{array}{r}32.8 \\
\pm 0.3\end{array}$ & $\begin{array}{r}29.7 \\
\pm 0.1\end{array}$ & $\begin{array}{r}23.0 \\
\pm 0.8\end{array}$ & $\begin{array}{r}12.5 \\
\pm 0.7\end{array}$ & $\begin{array}{c}7.7 \\
\pm 0.8\end{array}$ & $\begin{array}{c}0.0 \\
\pm 0.0\end{array}$ \\
\hline
\end{tabular}

Table 3 Point angle and distance A of the pallet lock 2 pulley from the beginning of the coordinate system 
Partial values of forces $F_{y i(x i)} / \mathrm{N}$ acting on the force sensor 15 , when pushing the pallet lock 2 pulley into the free space in front of the front vertical surface of the stop 3 , were (for $i=5$ measurements repeated under the same conditions) scanned by the measuring device Dewetron DS-NET with the DS-GATE central control unit, read on PC in software DEWESoft X2 SP5 (see Fig. 7), and recorded in Tab. 3.

Partial values of measured forces $F_{y i(x i)} / \mathrm{N}$, when pushing the pallet lock 2 pulley into the free space in front of the front vertical surface of the stop 3, for a given $x_{i} / \mathrm{m}$ position as well as the mean $F_{s y(x i)} / \mathrm{N}$ are graphically displayed in Fig. 8.

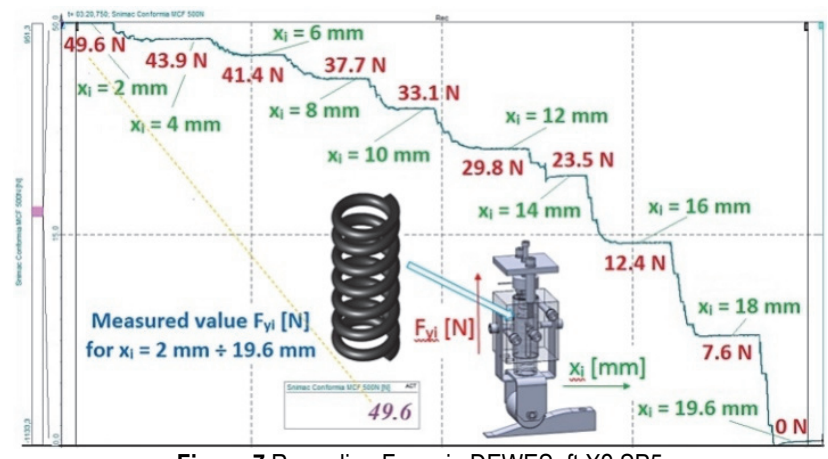

Figure 7 Recording Force in DEWESoft X2 SP5
The arithmetic mean $F_{s y(x i)} / \mathrm{N}$ was calculated using the measured values of forces $F_{y i(x i)} / \mathrm{N}$ and according to [4, 7] and the error margin of measured values $F_{y i(x i)} / \mathrm{N}$ was calculated according to [7], The last row of Tab. 3 contains results of measured values of forces $F_{y i(x i)} / \mathrm{N}$ in the form that is indicated by the Eq. (14).

$$
F_{y i(x i)}=F_{y s(x i)} \pm \kappa_{(x i)}
$$

\subsection{Applied Forces When Pushing the Lock Roller of the Fixation Mechanism Into the Gap Between the Stop Components}

The distance $l_{0} / \mathrm{m}$ between the moving part and the fixed part, see Fig. 9, of the horizontal positioning table 10 (i.e. the initial moment when the pallet lock pulley 2 engages the stop 3) is determined by the height $h_{z k} / \mathrm{m}$. The height $h_{z k} / \mathrm{m}$ is defined by the shortest distance of the outer surface of the pulley 2 from the top surface of the plate 9 of the horizontal positioning table 10 (see Fig. 9) that corresponds to the distance $\mathrm{h}_{2}[\mathrm{~m}]$ of the outer surface of the pallet lock roller 2 from the top surface of the front of the stop 3 (see Fig. 5). The height $h_{z k} / \mathrm{m}$ is adjusted on the pallet fixation lock tester by changing the distance $\mathrm{y}[\mathrm{m}]$ between the moving and the fixed part of the vertical positioning table 6, see Fig. 9.

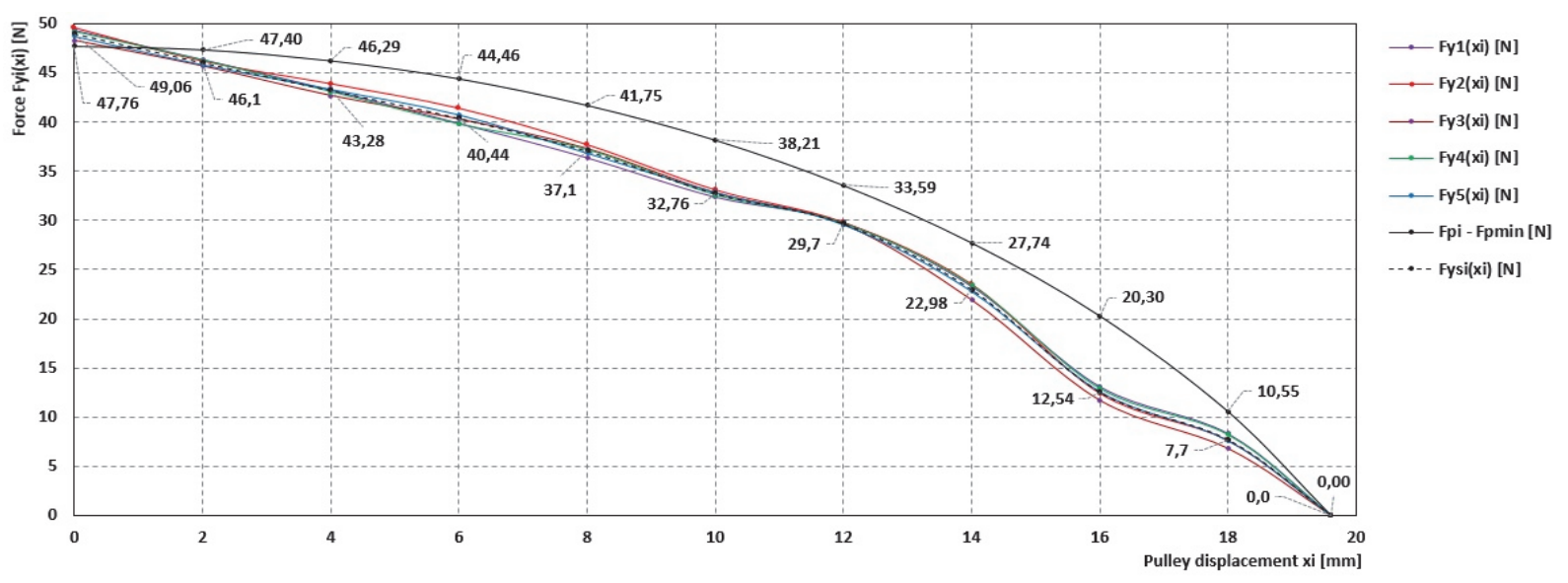

Figure 8 Vertical forces when pushing the pallet lock pulley roller into the space in front of the stop
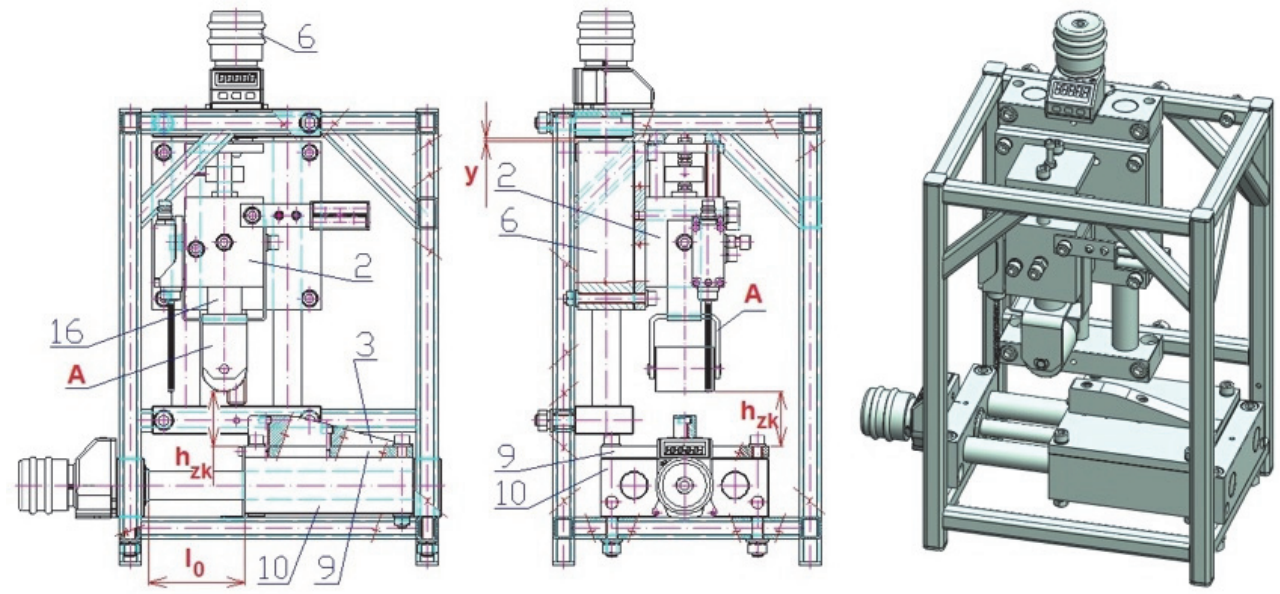

Figure 9 Vertical forces when pushing the pallet lock pulley roller into the space in front of the stop

By shortening the distance $1_{0}[\mathrm{~m}]$, the pipe 16 of the pulley bracket assembly A (see Fig. 9) is inserted into the pallet lock body 2 (while the free length $L_{0} / \mathrm{m}$ compression coil springs decreases). A force sensor which records the 
compressive force $F_{p} / \mathrm{N}$ of the compressed springs when pushing out the pallet lock pulley 2 from the space between the stops 3 [1] is mounted on the top of the structurally modified fixation lock 2 (see [1]).

Measurements were made on the handling unit fixation lock testing device, see Fig. 6, in order to obtain the real value of the applied forces $F_{y i} / \mathrm{N}$ by experimental procedure, derived by compression of the spring [5] when pushing the pulley of the pallet lock 2 out of the gap between the two faces of the stops 3 [1] The experiment was carried out as follows: The pulley of the pallet lock 2 was first guided to a distance of $x_{p} / \mathrm{m}$ from the origin of the coordinate system $\left[x_{0} ; y_{0}\right]$ (lower roller surface of the pallet lock 2, see point A in Fig. 10, was at $\left[x_{p} ; y_{0}=19.6 ; 0\right] \mathrm{mm}$, see Fig. 10) and then the moveable part of the horizontal positioning table 10 to which a stop had been attached 3, moved progressively by $\left(x_{p}-x_{i}\right) / \mathrm{m}$ in the horizontal plane.

Partial forces $F_{y i(x i)} / \mathrm{N}$ acting on the force sensor 15, when pushing the pulley of the pallet lock 2 from the free space in front of the front vertical surface of the stop 3; were (for $i=5$ repeated measurements under the same conditions) recorded in Tab. 4.

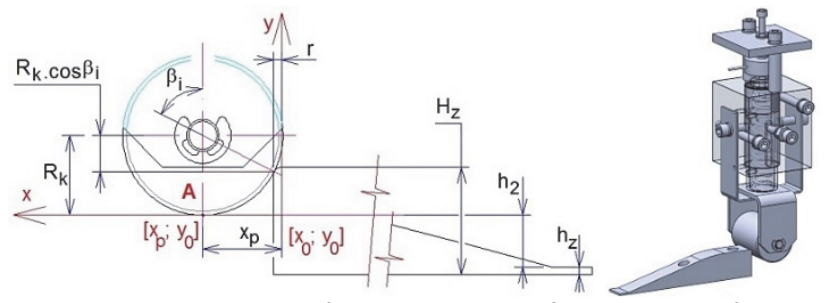

Figure 10 The Initial position of the pallet lock pulley 2 when pushing it from the free space onto the stop 3

Partial values of measured forces $F_{y i(x i)} / \mathrm{N}$, when pushing the pallet lock 2 pulley into the free space in front of the front vertical surface of the stop 3, for a given $x_{i} / \mathrm{m}$ position as well as the mean $F_{s y(x i)} / \mathrm{N}$ are graphically displayed in Fig. 11. Recording of measured forces $F_{y i(x i)} /$ $\mathrm{N}$ in DEWESoft X2 SP5 software environment giant Fig. 12.

\begin{tabular}{|c|c|c|c|c|c|c|c|c|c|c|c|c|}
\hline$x_{i} \cdot 10^{-3} / \mathrm{m}$ & \multirow{4}{*}{$\mathrm{i}$} & 0 & 2 & 4 & 6 & 8 & 10 & 12 & 14 & 16 & 18 & 19.6 \\
\hline$x_{p}-x_{i} / \mathrm{mm}$ & & 19.6 & 17.6 & 15.6 & 13.6 & 11.6 & 9.6 & 7.6 & 5.6 & 3.6 & 1.6 & 0 \\
\hline$y_{(x p-x i)} / \mathrm{mm}$ & & 0.00 & 2.65 & 5.10 & 6.97 & 8.44 & 9.60 & 10.49 & 11.17 & 11.63 & 11.91 & 12.00 \\
\hline$F_{p(x i)} / \mathrm{N}$ & & 74.6 & 74.6 & 85.2 & 94.9 & 102.3 & 108.2 & 112.8 & 116.4 & 119.1 & 122.0 & 122.4 \\
\hline$F_{p(x i)}-F_{p \min } / \mathrm{N}$ & & 0.0 & 10.6 & 20.3 & 27.7 & 33.6 & 38.2 & 41.8 & 44.5 & 46.3 & 47.4 & 47.8 \\
\hline \multirow{5}{*}{$F_{y i(x i)} / \mathrm{N}$} & 1 & 0.0 & 7.8 & 17.7 & 27.5 & 34.9 & 38.9 & 42.1 & 45.0 & 46.7 & 47.6 & 47.6 \\
\hline & 2 & 0.0 & 7.6 & 18.6 & 27.9 & 35.4 & 38.8 & 42.2 & 44.8 & 46.8 & 47.6 & 47.8 \\
\hline & 3 & 0.0 & 8.1 & 17.7 & 27.3 & 35.2 & 38.8 & 42.3 & 44.9 & 46.7 & 47.7 & 47.7 \\
\hline & 4 & 0.0 & 8.2 & 18.1 & 27.4 & 34.8 & 38.8 & 42.2 & 44.8 & 46.7 & 47.7 & 48.1 \\
\hline & 5 & 0.0 & 8.4 & 17.8 & 27.3 & 34.9 & 38.9 & 42.3 & 44.8 & 46.8 & 47.6 & 47.6 \\
\hline \multicolumn{2}{|l|}{$F_{y s(x i)} \pm \kappa_{(x i)} / \mathrm{N}$} & $0.0 \pm 0.0$ & $8.0 \pm 0.4$ & $18.0 \pm 0.5$ & $27.5 \pm 0.3$ & $35.0 \pm 0.3$ & $38.8 \pm 0.1$ & $42.2 \pm 0.1$ & $44.9 \pm 0.1$ & $46.7 \pm 0.1$ & $47.6 \pm 0.1$ & $47.8 \pm 0.3$ \\
\hline
\end{tabular}

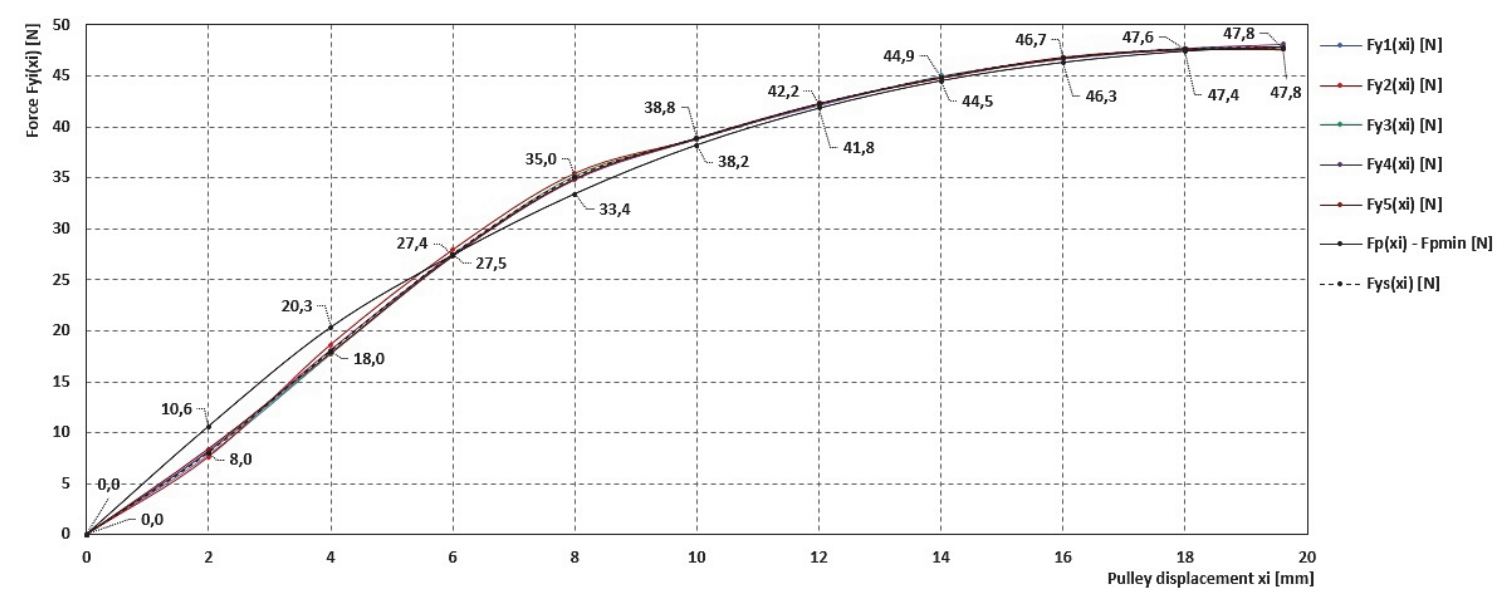

Figure 11 Vertical forces when pushing the pallet lock roller 2 onto the stop 3

\section{CONCLUSION}

The current situation and problem of operating an automatic parking house in the city Slaný is described in the introduction. It also states the basic prerequisites for the problem-free storing of vehicles in the parking house rack cells of the storage and mentions the technical requirements for the unloading of vehicles in fully automatic mode in the parking house. One of the key requirements is to ensure that the pallets (with or without parked vehicles) in the parking rack cells are locked in the specified position.

The pallets are fixed in the required position by the socalled pallet locking mechanisms. The pallet locking mechanism consists of two basic parts, the first is the "pallet lock", the second is a "stop". The pallet lock is installed in each cell of the parking rack, where it is fixed with screws to the horizontal beams of the steel rack structure. The stop, consisting of two so-called haunches (triangular cuboid shape), is fixed in two diagonal corners on the bottom surface of each pallet.

A 2D structural design, 3D model and physically assembled testing equipment fixation mechanism of handling units were made for the purpose of demonstrating the working of the pallet lock fixation mechanism and to obtain the true values of the vertical forces that are generated when rolling the pallet lock pulley over the sloped surface of the stop, and when the pallet lock pulley is pushed into the gap between two stop components. 
For the testing device of the fixation mechanism of the handling units, consisting of two positioning tables to which a pallet lock and a stop had been attached, experimental measurements were made to allow the values of the vertical forces acting on the pallet fixation mechanism to be obtained when loading/unloading the pallet with the vehicle into/from the parking rack cell.

The three basic operating states which the handling unit mechanism is subjected to during parking and delivery of the vehicle in an automatic parking house, i.e. rolling of the pallet lock roller over the sloped surface of the stop, pushing the pallet lock roller into the gap between the two stop components of the stop assembly, and pushing the pallet lock pulley out of the gap between the two stop components, were simulated on a testing device. The values of vertical forces were experimentally obtained for these three states, and were measured by the strain gauge force sensor MCF30 of the company CONFORIA, s.r.o., recorded by the DEWESoft DS-NET measuring device of the company DEWETRON and displayed on a PC in the software DEWESoft XP 5.0.

The measured values, for five repeated measurements under the same conditions, vertical forces for the three operating states of the handling unit mechanism, were recorded in tables, graphs and statistically evaluated by Student Distribution.

\section{Acknowledgements}

This work has been supported by The Ministry of Education, Youth and Sports of the Czech Republic from the Specific Research Project SP2021/53.

\section{REFERENCES}

[1] Hrabovsky, L. \& Molnar, V. (2020). Pallet fixing lock, determination of shear resistance and spring stiffness. Advances in Science and Technology Research Journal, 14(2), 190-197. https://doi.org/10.12913/22998624/119756

[2] Hrabovsky, L. \& Mlcak, T. (2020). Vertical Forces Acting on the Lock-Off Element of the Pallet Brake System. Advances in Science and Technology Research Journal, 14(1), 107-117. https://doi.org/10.12913/22998624/113607

[3] Hrabovsky, L. \& Mlcak, T. (2019). Forces Generated in the Parking Brake of the Pallet Locking System. Advances in Science and Technology Research Journal, 13(4), 181-187. https://doi.org/10.12913/22998624/111478

[4] Hrabovsky, L. \& Fedorko, G. (2020). Electromagnetic locking devices of car handling units. Scientific Journal of Silesian University of Technology. Series Transport, 107, 73-83. https://doi.org/10.20858/sjsutst.2020.107.5

[5] See https://www.hennlich.cz//fileadmin/_migrated/cz_Tla $\% \mathrm{C} 4 \% 8 \mathrm{Dn} \% \mathrm{C} 3 \% \mathrm{~A} 9$ pru\%C5\%B Einy_-_tabulky_ patent_1_6-2_8.pdf

[6] Seehttp://tenzometry.eu/comforia/index.php?nahled snimace $=7$

[7] Madr, V. \& Knejzlik, J. (1991). Fyzikálni méřeni-Physical measurements - In Czech. SNTL Praha, $304 \mathrm{str}$

[8] Hrabovsky, L. \& Dluhos, D. (2019). Calibration of Transducers and of a Coil Compression Spring Constant on the Testing Equipment Simulating the Process of a Pallet Positioning in a Rack Cell. Open Engineering, 9(1), 631640. https://doi.org/10.1515/eng-2019-0072

\section{Contact information:}

Leopold HRABOVSKÝ, doc., Ing., PhD

(Corresponding author)

VSB Technical University of Ostrava,

Faculty of Mechanical Engineering,

Institute of Transport

17. listopadu 2172/15, 70800 Ostrava- Poruba, Czech Republic

E-mail: leopold.hrabovsky@vsb.cz

\section{Tomáš MLČÁK, Ing., PhD}

VSB Technical University of Ostrava,

Faculty of Electrical Engineering and Computer Science,

Department of Electrical Engineering,

17. listopadu 2172/15, 70800 Ostrava - Poruba, Czech Republic

E-mail: tomas.mlcak@vsb.cz

Václav ŽÁČEK, Ing

KOMA - Industry s.r.o.x.

Ruská 514/41, 70602 Ostrava - Vítkovice, Czech Republic

E-mail: vaclav.zacek@komaindustry.cz 